\title{
Endogenous sunk costs and the geographic differences in the market structures of CPG categories
}

\author{
Bart J. Bronnenberg • Sanjay K. Dhar • \\ Jean-Pierre H. Dubé
}

Received: 4 December 2008 / Accepted: 6 October 2010 / Published online: 4 November 2010 (C) The Author(s) 2010. This article is published with open access at Springerlink.com

\begin{abstract}
We describe the industrial market structure of CPG categories. The analysis uses a unique database spanning 31 consumer package goods (CPG) categories, 39 months, and the 50 largest US metropolitan markets. We organize our description of market structure around the notion that firms can improve brand perceptions through advertising investments, as in Sutton's endogenous sunk cost theory. The richness of our data allow us to go beyond Sutton's bounds test and to study the underlying forces bounding concentration away from zero. Observed advertising levels escalate in larger US markets. At the same time, the number of advertised brands in an industry appears to be invariant to market size. Therefore, the size-distribution of brands across markets is characterized by bigger (i.e. more heavily advertised) as opposed to more brands in larger markets. Correspondingly, observed concentration levels in advertising-intensive industries are bounded away from zero irrespective of market size.
\end{abstract}

Keywords Market structure - Endogenous sunk costs • Advertising • CPG brand

JEL Classification $\mathrm{L} 11 \cdot \mathrm{L} 66 \cdot \mathrm{M} 30 \cdot \mathrm{M} 37 \cdot \mathrm{R} 12$

\footnotetext{
B. J. Bronnenberg

CentER, Tilburg University, Tilburg, The Netherlands

S. K. Dhar · J.-P. H. Dubé ( $ه)$

University of Chicago Booth School of Business, Chicago, USA

e-mail: jdube@chicagobooth.edu
} 


\section{Introduction}

We study the industrial market structure of branded consumer packaged goods (CPG), a sector of the food industry of considerable economic importance. Total domestic sales of the food industry reached roughly $\$ 950$ billion in 2004 , with almost $50 \%$ deriving from retail sales. ${ }^{1}$ A striking feature of the CPG industry is the large expenditures on advertising by the manufacturers. According to CMR, the CPG sector spent $\$ 12.4$ billion and $\$ 11.9$ billion respectively across all measured media in 2000 and 2001 respectively (Business Wire 2002). Our analysis exploits the geographic variation in CPG market shares across large US cities (Bronnenberg et al. 2007). Our goal herein is to characterize aspects of these cross-market differences in market structure that can be tied to marketing activity.

Following Sutton's (1991) Endogenous Sunk Costs (ESC) theory, we organize our description of market structure around an industry's advertising intensity. Advertising is assumed to increase the perceived quality of a brand. If advertising consists of a fixed and sunk investment, Sutton's theory predicts a competitive escalation in advertising levels, and hence perceived brand quality levels, in larger markets. In addition, the economies of scale in advertising limit the extent of entry and, consequently, bound the level of concentration away from zero even in very large markets. The two classic testable implications of the theory consist of measuring the relationship between the size of a market and the observed advertising intensity as well as the lower bound on market shares respectively (Shaked and Sutton 1983, 1987; Sutton 1991, 2003).

The theory also embodies a third testable implication that consists of measuring the relationship between the size of a market and the size-distribution of branded firms in a market. According to the theory, the competitive escalation in advertising should lead to larger brands (i.e. better brands with higher perceived quality), without an escalation in the number of brands. A variation on this prediction is that one might nevertheless observe an escalation in the number of fringe brands that do not advertise. This latter aspect of the theory was discussed through cases in Sutton (1991), but was not tested formally.

The predictions of the theory change as we alter the advertising cost function, even as we maintain the assumption that advertising increases consumer willingness-to-pay. Reducing the convexity of advertising costs (i.e. if advertising costs are born primarily as a variable rather than fixed cost) gradually eliminates the scale economies of advertising in large markets. In this case, larger markets would experience a competitive escalation in entry, as opposed to advertising investment, leading to a limiting concentration of zero (Berry and Waldfogel 2003). In an even simpler model in which entry costs are fixed at a constant level (e.g. set-up costs do not involve advertising), we would again observe a competitive escalation in entry in larger markets, with concentration

\footnotetext{
1"Food Retailing in the 21st Century-Riding a Consumer Revolution," The Food Marketing Institute, http://www.fmi.org/media/bg/FoodRetailing.pdf
} 
converging to zero (Shaked and Sutton 1987). Therefore, we can test amongst these different theories of the role of advertising by looking at the relationship between market size and the equilibrium level of advertising, the number of advertising firms and the lower bound on concentration.

To measure these various implications of the theory, we use a comprehensive longitudinal database consisting of marketing data for all the brands from 31 CPG categories, covering 39 months in the 50 largest city market areas, as designated by AC Nielsen. Unlike previous work using international markets, our narrower focus on markets within the US has the advantage of ensuring more consistency in the physical characteristics of a given brand across markets. The limited degree of physical product differentiation in many CPG product categories facilitates the attribution of market structure to these marketing investments. For a subset of 23 geographic markets, we match contemporaneous as well as historic advertising levels from several years prior to the sample. These are measures of media advertising which, in CPG industries, are generally used for branding purposes. The advertising data allow us to distinguish between industries based on the extent to which they invest in branding to build better brand quality perceptions. In addition to advertising effort, we also observe advertising prices by market, allowing us to control for differences in the cost of media advertising across markets. Since the data contain all the brands available in a market within each category, we can conduct a comprehensive cross-industry analysis of the relationship between market size and the distribution of advertised versus non-advertised brands.

The data exhibit industry-level geographic patterns that are consistent with the predictions of ESC theory and which collectively document several novel stylized facts about CPG industries and brands. The typical industry/market is concentrated. However, within an industry, the level of concentration varies considerably across markets and, in some cases, reaches very low levels. Also consistent with the theory, advertising levels escalate in larger markets. At the same time, the number of advertised brands does not increase in larger markets; although the number of non-advertised "fringe" brands increases with market size. Partitioning the industries into advertising intense and non-advertising intense groups, we find for the former that concentration is bounded away from zero irrespective of market size. For the latter, concentration falls towards zero in larger markets. These patterns are consistent with the ESC notion that advertising costs are fixed and sunk, creating economies of scale that persist even in very large markets. The patterns rule out an alternative theory in which advertising costs vary with the level of output. We also observe bigger brands (i.e., more heavily advertised) rather than more brands in larger markets. The lack of fragmentation rules out alternative models such as pure horizontal differentiation, on the demand side, and advertising as a relatively variable cost, on the supply side.

This collection of results contributes to a growing empirical literature testing game-theoretic models of industrial market structure formation. Our work follows an approach pioneered by Sutton (1991, 2003), who provided several detailed case studies testing the implications of sunk costs on market structures 
in the food industry across international markets. Our work is also related to a literature using structural models to study market structure when crucial market outcome data such as prices and sales are unavailable (Bresnahan and Reiss 1991; Berry 1992). The ESC theory has subsequently been used to describe market structures for US manufacturing industries (Robinson and Chiang 1996), and recently for several industry case studies including the supermarket industry (Ellickson 2004a, b), newspapers and restaurants (Berry and Waldfogel 2003), and banking (Dick 2004, Cohen and Mazzeo 2004). Our work is also related to the literature documenting the relationship between market size, entry and the size-distribution of firms (e.g. Bresnahan and Reiss 1991, Berry 1992 and Campbell and Hopenhayn 2004). Insofar as we observe more advertising in larger markets, our work is also related to the literature studying the geographic Silicon-Valley type agglomeration of firms (e.g. Krugman 1991, Ellison and Glaeser 1997, 1999).

The remainder of this paper is organized as follows. Section 2 outlines the theory and some comparative static predictions from a model of ESC. In Section 3, we describe our data. In Section 4, we test the industry-level predictions of basic ESC theory. Section 5 concludes.

\section{Endogenous sunk costs theory}

\subsection{Basic theory and industry level predictions}

In this section, we discuss the empirical predictions that arise from a basic model of endogenous sunk costs. Following the discussion of the model, we clarify which forms of advertising contribute to the creation of brands in CPG industries and why these investments may indeed be characterized as fixed and sunk.

The basic results are based on the perfect equilibrium of a three-stage game. In the first stage, firms decide whether or not to enter an industry which involves paying a constant sunk set-up cost. In the second stage, firms strategically choose their brand's positioning. In a model with advertising, this decision would involve choosing a sunk investment level in advertising for the purposes of increasing the perceived quality of the brand. In a model without advertising, this stage might simply involve firms costlessly choosing their brands' positions in a horizontally-differentiated product space. In the third and final stage, firms compete on prices (Bertrand Nash equilibrium).

In the following discussion, we summarize the details of the model and the results proved formally in Shaked and Sutton (1987). We provide some technical details in Appendix A. Several crucial assumptions are required. First, advertising raises a consumers' willingness-to-pay for a brand. Second, the burden of advertising falls more on fixed than variable costs. This seems like a reasonable assumption for the CPG markets in which advertising decisions are made in advance of realized sales. It is unlikely that advertising spending would have a large influence on marginal (production) costs of a branded 
good. ${ }^{2}$ In a subsection below, we provide more details about the nature of advertising and the plausibility of these assumptions for CPG industries. In more general consumer settings, these assumptions may not be innocuous. Berry and Waldfogel (2003) examine the role of this assumption for market structure. In the restaurant industry, where they find that quality is borne mainly in variable costs, they find that the range of observed quality levels rises with market size while market shares fragment with market size. In contrast, for the newspaper industry, where they expect quality to be a fixed cost, they observe average quality rising with market size without fragmentation.

In a purely horizontally-differentiated market, Shaked and Sutton (1987) prove that concentration converges to zero as market size increases. The intuition is that in a model where firms bear only constant fixed entry costs, economies of scale cease to matter in very large markets, which allows for a proliferation in product entry. In a Hotelling model, for example, increasing the mass of consumers along the horizontal continuum leads to a limiting result where the entire continuum is served and all firms earn arbitrarily small shares.

In contrast, as market size increases for industries in which firms can make fixed and sunk investments in quality (i.e. vertical attributes), we do not see an escalation in entry. Instead, we see a competitive escalation in advertising spending to build higher-quality products. The intuition for this result is that advertising creates a form of vertical product differentiation. Even with only a slight quality advantage, the highest-quality firm will always be able to garner market share and earn positive economic profits by under-cutting lower quality rivals. The escalation in advertising implies that economies of scale matter even in very large markets and, hence, only a finite number of firms enter even in the limit.

The distinction between the prediction for a model of horizontal versus vertical product differentiation indicates that product differentiation per se is insufficient to explain concentration. When firms cannot build verticallydifferentiated brands (by advertising) we expect markets to fragment as market size grows. In contrast, when firms can invest to build verticallydifferentiated brands, we do not expect to see market fragmentation, but rather an escalation in the amount of advertising and the perseverance of a concentrated market structure. These predictions are robust to a very wide class of discrete choice models of demand with horizontal and vertical product differentiation.

Sutton (1991) discusses a hybrid case that arises in markets where consumers may be segmented according to those who derive utility from the vertical attribute (i.e. brand quality) and those who do not. In such a market, it is possible to sustain firms that do invest in the endogenous sunk cost as well as firms that do not. In the limit, these two subsegments of advertised and

\footnotetext{
${ }^{2}$ The main driving force for CPG private labels and store brands is the fact that one can frequently mimick the national brand physically without the overhead required to build the brand name.
} 
non-advertised brands diverge to two independent market structures. As market size grows the former set of firms will have a concentration level bounded below. However, concentration for the latter set of firms will converge to zero. In this respect, the theory provides differential predictions for firms that advertise and firms that do not.

The results above generate a basic set of predictions for long-run market structure. In industries characterized by substantial endogenous fixed and sunk investments, such as advertising, we expect concentration to be bounded below even as the size of the market increases in the limit. However, in the absence of these endogenous sunk investments, we would expect concentration to converge to zero as the market size increases in the limit. Finally, if advertising consists of variable rather than fixed costs, we would then expect to see concentration converge to zero in larger markets for advertising intense industries.

\subsection{Advertising as an endogenous sunk cost in CPG industries}

We now briefly discuss the role of brand advertising via television media, the investment we attribute to the ESC model above. We also discuss trade promotions and $\mathrm{R} \& \mathrm{D}$, two other candidate investments that we do not believe lead to the market structure patterns observed in the CPG data.

For the purposes of building brand perceptions and boosting consumer willingness-to-pay for brands, CPG firms typically use media advertising. Since media advertising is determined in advance of sales, it corresponds reasonably well with the fixed and sunk cost structure of the theory in the previous subsections. In our analysis below, we use measures of media advertising to capture a firm's advertising effort.

Based on discussions with industry experts, we learned that CPG firms strategically set their advertising plans by geographic area and, as a result, advertising spending for a brand can vary significantly across markets. ${ }^{3}$ Brand managers often allocate advertising dollars across markets based on the relative brand strength, as measured by a brand development index. Managers can weight their spending more towards strong markets that represent a disproportionate fraction of the sales volume for their brand (when compared to the proportion of the target market population in that geography). In addition, brand managers may want to deliver locally customized advertising messages as the relevance of the benefits offered by a brand may vary across markets. For example, snow tires are not relevant in a warmer climate and the product and/or the associated marketing program is not targeted towards all geographies. For the food industries in this paper, media advertising consists primarily of spot and local cable television. Brand managers can achieve geographic targeting through local spot and local cable advertising; but they can also achieve this through national spot advertising, i.e., network advertis-

\footnotetext{
${ }^{3}$ The authors spoke with several industry experts from advertising agencies, such as Millward Brown and JWT, as well as from CPG marketing divisions, such as Kraft and Unilever.
} 
ing that is not shown in all markets (Kantar Media Report, May 26, 2010). ${ }^{4}$ Broadcast networks can also offer different clearance rates, the percentage of the markets or network's local station affiliate network that has agreed to carry the programming in which the advertisement is broadcast, allowing a brand to advertise in wide portions of the country but not in markets that brands might want to underweight or avoid. Accordingly, Miller Brewing, for example, has divided the US into 61 sub-markets, each of which has its own "highly individual plan."

There are several reasons for which we do not believe promotional spending would lead to the same impact on market structure as brand advertising. Promotional investments by CPG manufacturers consist of funds allocated to "the trade" (i.e. retailers) primarily for the purposes of passing pricecuts to consumers (Blattberg and Neslin 1990). A recent Nielsen survey of manufacturers indicates promotional spending primarily as a means to increase volume. ${ }^{6}$ Blattberg and Neslin (1990) explain that there is some evidence that promotions may weaken brand attitude and, hence, could possibly lower consumer willingness-to-pay. Finally, the cost structure of promotions is primarily variable since the total costs of price-cuts vary with the levels of sales. As discussed in Berry and Waldfogel (2003), this type of cost structure would lead to fragmentation as opposed to concentration in very large markets.

Finally, we also find it unlikely that $R \& D$ investments would influence market structure in CPG industries. Sutton (1991) referred to both advertising and $R \& D$ as general potential sources of endogenous sunk costs. However, Andras and Srinivasan (2003) estimate that advertising intensity for consumer goods averages $5.6 \%$ of sales revenue, while $R \& D$ intensity is $0.7 \%$ of sales revenue. Hence, we focus our analysis on advertising.

\subsection{Brand advertising and consumer willingness-to-pay}

We now provide evidence that advertising has been found to increase consumer perceptions of brand quality and to raise their willingness-to-pay, much like a vertical characteristic in a model of vertical product differentiation. Practitioners believe that spending more money on "more and better advertising" will increase brand sales (Advertising Age 1994).

Many examples exist in the context of CPGs that demonstrate that branding does influence the perceived quality of a product and correspondingly consumer willingness-to-pay. For example, Keller (2003, p. 62) summarizes the results of taste tests using leading beer products such as Budweiser, Miller Lite, Coors and Guinness. In a blind taste test (i.e. where consumers are not

\footnotetext{
${ }^{4}$ Kantar Media News Report, May 26, 2010, "Kantar Media reports U.S. advertising expenditures increased $5.1 \%$ in the first quarter of 2010".

${ }^{5}$ See "National Brand, Local Branding" at http://www.sabmiller.com/SABMiller.

6"Summary: 2003 Trade Promotion Practices", Consumer Insight, Vol. 6(2), summer 2004, 28-34. http://www2.acnielsen.com/pubs/documents/2004_q3_ci.pdf
} 
aware of the brand identities), the results indicate no perceived differentiation between these products except for Guinness, which is found to be quite different from other beers in the sample. However, in a separate taste test in which consumers know the brand names, the results indicate considerable differentiation between all the brands. In a similar beer study, Allison and Uhl (1964) find that consumers report very different quality rank-orderings on the same sets of products depending on whether or not the brand identities of the products are known. They conclude that, in the case of beer, brands are more relevant for product rankings than physical characteristics. A similar outcome was observed with the 1985 launch of "New Coke," a reformulation of the flavor syrup of Coca-Cola's flagship product. The launch was ultimately labeled the "marketing blunder of the century." Nevertheless, the "New Coke" formula adopted was preferred in blind taste tests by 200,000 consumers. ${ }^{7}$

A related literature demonstrates that brand advertising specifically influences consumer perceptions of brand quality. For instance, consumers exposed to advertising change their brand evaluations favorably towards the advertising brand if they remember information from the advertising (Keller 1987). Similarly, brand awareness increases through advertising (Hoyer and Brown 1990) and repeated brand advertising increases the chance of a brand entering a consumer's consideration set (Nedungadi 1990). The influence of advertising on brand preferences and choice has been shown to persist even in mature product categories (D'Souza and Rao 1995). More specifically, Chakravarti and Janiszewski (2004) find that brand advertising can reduce the price elasticity of demand for specific products in commodities markets, hence isolating the role of brand influence in otherwise homogenous products settings.

\section{Data}

We use AC Nielsen scanner data for $31 \mathrm{CPG}$ industries in the 50 largest AC Nielsen-designated Scantracks ${ }^{8}$ (see Dhar and Hoch 1997, for a description of similar data). These are the same data used in the two companion papers, Bronnenberg et al. (2007, 2009). We follow the convention of most CPG practitioners who use AC Nielsen data and treat the 50 scantracks as independent markets. This practice also has a legal precedent in the merger trial involving Coca-Cola and Dr. Pepper, in which according to the courts the Nielsen Scantracks are a legally valid market definition (F.T.C. v. CocaCola Co., 641 F. Supp. 1128 1986). Finally, the geographic areas represented by a typical Scantrack are consistent with the supermarket distribution

\footnotetext{
${ }^{7}$ See story "Coke Lore" at:http://www2.coca-cola.com/heritage/cokelore_newcoke.html.

${ }^{8}$ Each Scantrack covers a designated number of counties, with an average of 30 and a range of 1 to 68 . All markets include central city, suburban and rural areas.
} 
regions designated in Ellickson (2004a). Hence, on the supply side, our market definitions correspond to the manner that CPG practitioners define markets when making decisions. Also, on the demand side, it is unlikely that consumers arbitrage differences in brand marketing by traveling to other markets to buy CPG products.

The industries in the database collectively account for roughly \$26 Billion in annual national revenues. The data are sampled at four-week intervals between June 1992 and May 1995. The CPG industries covered are all large industries representing a wide range of both edible grocery and dairy products. For each market, time period and industry, we observe sales, prices, and promotional activity levels for each of the brands. Brand sales are measured in "equivalent units", which are scaled measures of unit sales provided by AC Nielsen to adjust for different package sizes across brands. We compute a brand's market share by dividing its sales (in equivalent units) by the total sales (in equivalent units) for the industry in a given market and time period. The promotion data break-down the total equivalent unit sales of a brand by the promotional conditions under which they were sold. For our analysis, we construct a promotion variable by computing the fraction of a brand's sales that was sold under any form of in-store promotion including price-cuts and merchandising such as feature advertising and in-aisle displays. In addition to our geographic market (Scantrack) level data, we also have analogous data at the retailer account level for those retailers in each market with local annual revenues exceeding \$2MM. Account level data encompass all stores in the retail chain for the geographic market. There are 67 such retailers in the data, which jointly cover 48 of the 50 Nielsen markets.

In the data, a "brand" encompasses all the stock-keeping units (SKUs) sold bearing a given brand name. For instance, in the ground coffee category, the Folgers brand aggregates all the SKUs with the Folgers label which embodies a wide array of can sizes. Similarly, in the yogurt category, the Yoplait brand aggregates all pack sizes and yogurt flavors sold with the Yoplait name on the label. Since brand advertising decisions are made at the brand level and not at the SKU level (i.e. we do not see television advertising for a specific flavor of Yoplait yogurt), we are not concerned about the multi-product nature of the firms in such instances. Even in cases where a CPG conglomerate owns multiple brands, separate management teams typically oversee the marketing of each brand in the portfolio. For instance, Folgers is owned by $\mathrm{P} \& \mathrm{G}-\mathrm{a}$ large brand conglomerate, but has its own separate management team responsible for its marketing. Similarly, according to the company website, Ben \& Jerry's continues to operate "to a large extent independently" and "separately from Unilever's current U.S. ice cream business" even after its acquisition by Unilever. ${ }^{9}$ Hence, we treat each brand in our database as a single product firm.

\footnotetext{
${ }^{9}$ For additional documentation, see http://www.benjerry.com/our_company/press_center/press/ join-forces.html.
} 
Table 1 The structure of the data set

\begin{tabular}{ll}
\hline $\begin{array}{l}\text { Industry } \\
\text { groupings }\end{array}$ & $\begin{array}{l}\text { Bread and bakery, candy and gum, dairy products, frozen entrees and side } \\
\text { dishes, frozen and refrigerated desserts, non-alcoholic beverages, packaged } \\
\text { dry groceries, processed canned and bottled foods, refrigerated meats }\end{array}$ \\
\hline Markets & Albany, Atlanta, Baltimore, Birmingham, Boston, Buffalo, Charlotte, \\
& Chicago, Cincinnati, Cleveland, Columbus, Dallas, Denver, Detroit, \\
& Des Moines, Grand Rapids, Harrisburg, Houston, Indianapolis, \\
& Jacksonville, Kansas City, Los Angeles, Louisville, Little Rock, Memphis, \\
& Miami, Milwaukee, Minneapolis, Nashville, New Orleans/Mobile, \\
& New York, Oklahoma City/Tulsa, Omaha, Orlando, Philadelphia, Phoenix, \\
& Pittsburg, Portland, Raleigh/Durham, Richmond/Norfolk, Sacramento, \\
& San Antonio, San Diego, Seattle, San Francisco, St. Louis, Syracuse, \\
& Tampa, Washington \\
& A \& P, Super Fresh, ABCO, ACME, Albertson's, Almac's, AWG, BiLo, \\
& Big Bear, Bruno's, Del Champs, Demoulas Market Basket, Dominick's, \\
& Eagle Food Centers, Farm Fresh, Farmer Jack, Fiesta Mart Inc., Food4Less, \\
& Food Lion, Food Mart, Fred Meyer, Gerland's, Giant, Giant Eagle, \\
& Grand Union, Great American, H.E.B., Harris Teeter, Harvest Foods, \\
Retailers & Homeland Food Stores, Hughes Market, Hy Vee Foods, Jewel Food Stores, \\
& Kash N Karry, King Soopers, Kohl's, Lucky, Lucky Stores, Minyard Food Stores, \\
& National, Omni, P\&C, Pathmark, Publix, Purity Markets, Raley's, Ralphs, \\
& Randall's, Riser Foods Inc., Safeway, Save Mart, Schnuck's, Schwegmann, \\
& Sentry Markets, Shaw's, Shoprite, Smith's Food and Drug Centers, Smitty's, \\
& Star Market, Stop and Shop, Super Fresh, Kroger, Tom Thumb, Tops Markets, \\
& Vons, Waldbaum's, Wegman's Food Markets, Winn Dixie \\
\hline
\end{tabular}

${ }^{a}$ We classify the 31 industries into nine groupings

To control for brand advertising, we obtain media advertising data from Nielsen Media Research. The advertising data consist of advertising intensity levels measured in gross rating points (GRPs) ${ }^{10}$ for 23 of the geographic markets. Thus, we observe the advertising GRPs for each brand in each time period for these 23 markets. The distribution of population sizes across these 23 markets is comparable to the distribution across all 50 scantracks. One advantage of using GRP data is that they are normalized measures and can be used to compare advertising intensity across markets of different size. Advertising expenditure levels can still be computed using the list price (by market and quarter) of GRPs reported in the Media Market Guide.

Table 1 lists the CPG food categories covered, along with each of the geographic markets and retailers in the database. In the analysis below, we report results across the 31 industries. However, for confidentiality reasons, we are unable to name each of these 31 categories. Instead, we use a 9-group classification to identify the industries. For example, the bread industry is included in the "Bread and Bakery" group, the candy industry is included in the "Candy and Gum" group, the butter and cream cheese industries are

\footnotetext{
${ }^{10}$ GRPs are the CPG industry standard for measuring media advertising. GRPs are calculated by multiplying reach and frequency. Reach measures the proportion of the target market that has seen the firm's advertising at least once. Frequency measures the average number of times individuals in the target market saw the ad within a purchase cycle.
} 
contained in the "Dairy Products" group, the pizza industry is contained in the "Frozen Entrees/Side Dishes" group, the frozen toppings industry is contained in the "Frozen/Refrigerated Desserts" industry, the juices and coffee industries are contained in the "Non-Alcoholic Beverages" group, the pasta industry is contained in the "Packaged Dry Groceries" group, the mayonnaise and fruit spreads industries are contained in the "Processed Canned/Bottled Foods" group, and dinner sausages are contained in the "Refrigerated Meats" group.

To maintain consistency with previous research, we measure a market's size as its profit potential scaled by the exogenous set-up costs required for an entrant operating a plant at minimum efficient scale. Thus, we control for the fact that we expect the potential for entry and escalation in a market to differ across industries with different exogenous set-up costs. Our main measure of market profit potential is the natural logarithm of the observed total industry revenues. We also use the natural logarithm of the population of a geographic market to ensure our results are robust to a truly exogenous measure of market size. ${ }^{11}$ As in Sutton, we measure the set-up costs as the capital requirement of a firm operating at minimum efficient scale. We refer the reader to Sutton (1991, Chapter 4) for a thorough discussion of this approach and its limitations. We use data from the 1997 economic census at the industry-level for the manufacturing sector. For each industry, we compute the average value of depreciable assets by dividing the reported "Gross Book Value of Depreciable Assets at Beginning of Year" by the reported "Number of Companies." A limitation of this approach is that we effectively use the average-sized firm as the proxy for minimum efficient scale, rather than the median-sized firm.Although not reported in the paper, all of our main results are qualitatively similar if we assume that advertising is the only relevant fixed cost and we do not normalize our market sizes by proxies for the exogenous set-up costs.

\section{Concentration and sunk investments in advertising}

In this section, we examine whether the main predictions from the ESC framework fit our data. We first discuss the geographic concentration patterns both across and within the 31 industries. Next, we test the basic predictions of the theory by examining the impact of market size on (1) advertising levels, (2) brand proliferation, and (3) market concentration.

\subsection{Concentration in CPG industries}

To measure concentration, Sutton (1991) used the 4-firm concentration ratio, $C_{4}$, which is a popular measure in practice. However, the basic theory

\footnotetext{
${ }^{11}$ The normalization of population by the dollar value of set-up costs is not entirely intuitive, but we view the robustness check as important nevertheless.
} 
predicts a lower bound on concentration, which requires at least one firm to capture a non-zero market share irrespective of market size. To conform most closely with Sutton's theory, we use the one-firm concentration ratio, $C_{1}$, as our definition of concentration in each industry and geographic market. $C_{1}$ measures the maximum market share across brands in an industry/market. To conserve space, we report results for $C_{1}$; however all of our findings are robust to other standard measures of market concentration such as $C_{2}, C_{3}$ or the Herfindal Index. Also to conform more closely with the theory, we look at the concentration of sales output, as opposed to production output.

Table 2 summarizes the concentration levels across industries and markets. For each industry, we compute the within-market mean concentration level and we report the mean, standard deviation, minimum and maximum across markets. On average, all of these industries look fairly concentrated in terms of $C_{1}$. However, within an industry, concentration varies considerably across markets. The average range of concentration levels (difference between crossmarket maximum and minimum $C_{1}$ ) across industries is 0.41 . Hence, on

Table 2 One firm concentration statistics for a subset of the 31 industries ( $N=50$ markets)

\begin{tabular}{llllll}
\hline Industry group & $\begin{array}{l}\text { Industry } \\
\text { group member }\end{array}$ & Mean C1 & Std C1 & Min C1 & Max C1 \\
& 1 & 0.13 & 0.06 & 0.05 & 0.31 \\
\hline Bread and bakery & 1 & 0.32 & 0.08 & 0.12 & 0.49 \\
Candy and gum & 1 & 0.37 & 0.12 & 0.06 & 0.61 \\
Dairy products & 2 & 0.26 & 0.10 & 0.11 & 0.53 \\
Dairy products & 3 & 0.65 & 0.07 & 0.51 & 0.78 \\
Dairy products & 4 & 0.28 & 0.13 & 0.06 & 0.67 \\
Dairy products & 5 & 0.26 & 0.10 & 0.11 & 0.59 \\
Dairy products & 6 & 0.57 & 0.14 & 0.31 & 0.77 \\
Dairy products & 7 & 0.26 & 0.07 & 0.15 & 0.40 \\
Dairy products & 8 & 0.45 & 0.17 & 0.22 & 0.94 \\
Dairy products & 9 & 0.33 & 0.08 & 0.19 & 0.60 \\
Dairy products & 1 & 0.20 & 0.05 & 0.12 & 0.32 \\
Frozen entrees/side dishes & 2 & 0.37 & 0.08 & 0.22 & 0.57 \\
Frozen entrees/side dishes & 1 & 0.56 & 0.15 & 0.21 & 0.79 \\
Frozen/refrigerated desserts & 2 & 0.32 & 0.09 & 0.15 & 0.63 \\
Frozen/refrigerated desserts & 1 & 0.37 & 0.07 & 0.25 & 0.57 \\
Non-alcoholic beverages & 2 & 0.32 & 0.06 & 0.15 & 0.37 \\
Non-alcoholic beverages & 1 & 0.05 & 0.24 & 0.43 \\
Packaged dry groceries & 2 & 0.57 & 0.06 & 0.12 & 0.39 \\
Packaged dry groceries & 3 & 0.55 & 0.12 & 0.33 & 0.87 \\
Packaged dry groceries & 1 & 0.20 & 0.04 & 0.42 & 0.69 \\
Processed canned/bottled foods & 2 & 0.48 & 0.08 & 0.13 & 0.32 \\
Processed canned/bottled foods & 3.34 & 0.67 \\
Processed canned/bottled foods & 3 & 0.32 & 0.07 & 0.19 & 0.45 \\
Processed canned/bottled foods & 4 & 0.36 & 0.11 & 0.19 & 0.69 \\
Processed canned/bottled foods & 5 & 0.48 & 0.14 & 0.23 & 0.76 \\
Processed canned/bottled foods & 6 & 0.53 & 0.16 & 0.30 & 0.90 \\
Processed canned/bottled foods & 7 & 0.31 & 0.10 & 0.11 & 0.43 \\
Processed canned/bottled foods & 8 & 0.11 & 0.14 & 0.63 \\
Refrigerated meats & 1 & 0.14 & 0.11 & 0.78 \\
Refrigerated meats & 2 & 0.09 & 0.12 & 0.50 \\
Refrigerated meats & 3 & & &
\end{tabular}


average, the largest market share in an industry varies by as much as 41 share points across geographic areas. The column reporting the minimum concentration levels reveals that while some industries remain concentrated across all markets (i.e. never fall below $40 \%$ ), other industries have markets where concentration falls as low as 0.05 and 0.06 . In summary, we observe strong differences in concentration both across industries and markets. Next, we will examine whether the predictions of ESC theory fit our data and hence account for this variation in concentration across and within industries.

\subsection{Advertising escalation}

If advertising costs are fixed and sunk, as in the ESC model, one would expect to observe an escalation in advertising in larger markets. We define the advertising intensity of an industry by looking at the total advertising investment during and before the sample, 1989 to 1995, scaled by total insample industry revenues, 1993 to 1995. The upper and lower quartiles of industry advertising intensity designate the sets of advertising intense versus non-advertising intense industries. ${ }^{12}$ A potential concern with advertising expenditures is that the price of advertising also varies across markets. In particular, our largest markets (e.g. New York and LA) also have the highest advertising prices as measured by list prices per GRP. We can control for this problem by conducting our analysis based on GRPs, rather than advertising expenditures. The advantage of the GRP is that it is a normalized measure, making it more comparable across markets of differing size.

Figure 1 illustrates the escalation in advertising for larger markets. In the upper half of the figure, we plot, by market, each industry's average advertising expenditure per brand, between 1993 and 1995 against market size measured as the logarithm of revenues over the exogenous set-up costs. The figure drops the bottom quartile of industries based on advertising intensity as advertising expenditures tend to remain either zero or close to zero across markets in these industries. ${ }^{13}$ To measure the market size elasticity of advertising, we regress the logarithm of each industry's average advertising expenditure in a market on the corresponding de-meaned logarithm of market size and industry fixedeffects. We obtain a statistically significant elasticity of roughly one. ${ }^{14}$ We plot the predicted advertising levels in the figure to visualize this escalation. The results indicate that, on average, CPG firms advertise more in larger markets, as predicted by the theory.

\footnotetext{
${ }^{12}$ This may not an ideal measure of advertising intensity as it is based on equilibrium outcomes of advertising and sales. A preferable approach would be to use some measure of the marginal effectiveness of advertising in an industry. But, such measures are not readily available.

${ }^{13}$ Although not reported, the same pattern arises if we use GRP levels instead of spending levels. Since advertising prices are higher in larger markets, this confirms that escalation in spending is not merely an artifact of ad costs.

${ }^{14}$ The elasticity is lower, but nevertheless significantly positive if we use GRP levels instead of expenditure levels. Hence, the escalation is not merely an artifact of higher prices in larger markets.
} 
(a) Advertising expenditure per month versus market size excluding the bottom quartile industries based on advertising intensity. The solid line corresponds to the predicted advertising levels from a regression of log-advertising on industry fixed-effects and market size.
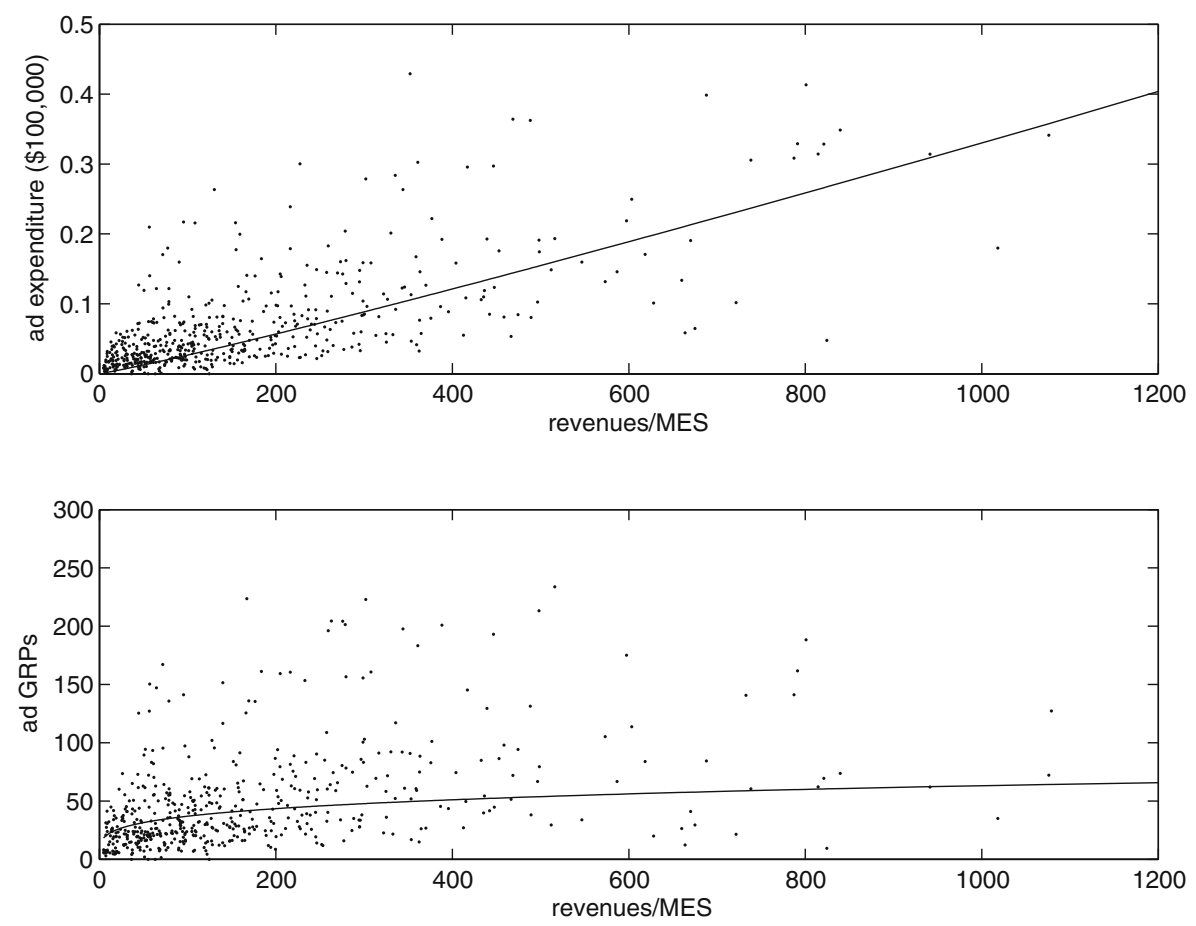

Fig. 1 Advertising versus market size excluding the bottom quartile industries based on advertising intensity. The top panel uses mean monthly advertising expenditures per firm in $\$ 100,000$. The lower panel uses mean monthly advertising GRPs per firm. The solid line in each plot corresponds to the predicted advertising levels from a regression of log-advertising on industry fixed-effects and market size

The lower half of Fig. 1 replicates the advertising escalation result using GRPs instead of expenditures. As discussed above, this measure is more appropriate for comparisons across markets of differing size. Not surprisingly, the market size elasticity is lower since we have removed the effect of rising prices. However, we still see an escalation in advertising in markets of increasing size. This result is particularly striking given that ad prices are also increasing in the larger markets. In spite of rising advertising costs, we still see an escalation in the amount of advertising effort exerted in larger markets.

\subsection{Brand proliferation}

In addition to advertising escalation, ESC theory predicts a non-proliferation in entry. The theory also distinguishes between advertised and non-advertised brands. Specifically, the number of advertised brands does not escalate in larger markets. However, the number of non-advertised "fringe" products 


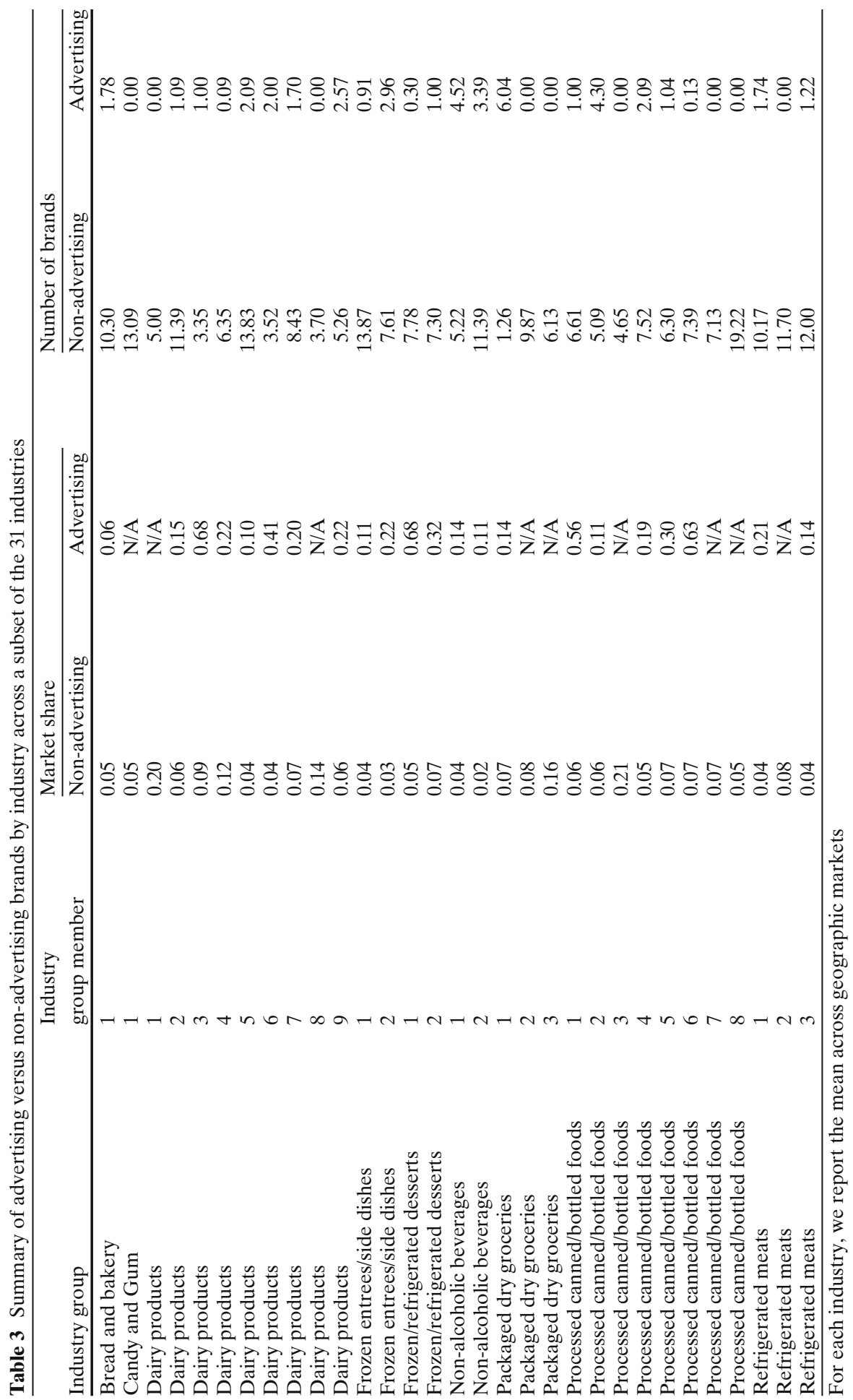


Table 4 Summary of advertising versus non-advertising brands across all 31 categories

\begin{tabular}{|c|c|c|c|c|c|c|}
\hline & \multicolumn{3}{|c|}{ Market share } & \multicolumn{3}{|c|}{ Number of brands } \\
\hline & Mean & Min & $\operatorname{Max}$ & Mean & Min & Max \\
\hline Advertising brands & 0.27 & 0.06 & 0.68 & 1.39 & 0 & 6.04 \\
\hline Non-advertising brands & 0.07 & 0.02 & 0.21 & 8.14 & 1.26 & 19.22 \\
\hline
\end{tabular}

does escalate in larger markets. Sutton (1991) provides anecdotal support for this phenomenon in his case studies, but is unable to provide econometric evidence of this phenomenon across industries. In his case study of the supermarket industry, Ellickson (2004b) documents evidence of a similar twotiered market structure with dominant and fringe firms in the context of supermarkets. He finds that the number of high quality supermarkets remains fixed across markets of varying size, whereas the number of low-quality supermarkets increases in larger markets. A novel aspect of our database is that we are able to document econometric support for this phenomenon across a large cross-section of CPG industries.

Most of the industries exhibit a co-existence of brands that advertise and brands that do not. Table 3 reports each industry's cross-market average number of brands and market share levels for advertised versus non-advertised brands. We drop the private labels to focus on the proliferation of small local brands; although adding private labels would merely strengthen our results below. Table 4 summarizes these findings. The historic pre-sample advertising levels are used to proxy for investment. Hence, our classification of advertising versus non-advertising brands is based on whether a brand invested in advertising during the years $1989-1993 .{ }^{15}$ In most industries, we tend to observe considerably more non-advertised brands than advertised brands. Interestingly, the market share of an advertised brand is typically considerably larger than that of a non-advertised brand.

We next test the proliferation prediction by pooling the 31 industries and 23 geographic markets for which advertising is observed. $N_{i m}$ denotes the number of brands that advertise in industry $i$ and market $m$. Since $N_{i m}$ is a count variable, it is assumed to be distributed Poisson with mean $\lambda_{i m}$ where:

$$
\lambda_{\text {im }}=\exp \left(X_{\text {im }} \beta\right)
$$

and $X_{i m}$ contains industry fixed-effects and market sizes (the natural logarithm of either the population to set-up costs ratio or the revenue to set-up costs ratio). We then re-run the regression (1) using the number of unadvertised brands as the dependent variable. The results in Table 5 indicate a statistically insignificant relationship between market size and the number of advertising

\footnotetext{
${ }^{15}$ For the results reported, we define an advertising brand as one that advertises during each year in our data. A non-advertising brand is defined as one that never advertised during the sample years. Although not reported, all of our results are robust to less conservative definitions that consider brands that "occasionally" advertise (i.e. up to less than half the time) and brands that "occasionally" do not advertise (i.e. less than half the time).
} 
Table 5 Brand proliferation and market size

\begin{tabular}{|c|c|c|c|c|c|c|c|c|}
\hline \multicolumn{9}{|c|}{ Number of brands versus $\log ($ revenues/set-up costs $)$} \\
\hline & \multicolumn{4}{|c|}{ Market size $=$ revenue/set-up costs } & \multicolumn{4}{|c|}{ Market size $=$ population $/$ set-up costs } \\
\hline & \multicolumn{2}{|l|}{$\begin{array}{l}\text { Advertising } \\
\text { brands }\end{array}$} & \multicolumn{2}{|c|}{$\begin{array}{l}\text { Non-advertising } \\
\text { brands }\end{array}$} & \multicolumn{2}{|l|}{$\begin{array}{l}\text { Advertising } \\
\text { brands }\end{array}$} & \multicolumn{2}{|c|}{$\begin{array}{l}\text { Non-advertising } \\
\text { brands }\end{array}$} \\
\hline & Coefficient & s.e. & Coefficient & s.e. & Coefficient & s.e. & Coefficient & s.e. \\
\hline Intercept & 0.89 & 0.14 & 1.58 & 0.09 & 0.95 & 0.13 & 1.70 & $\overline{0.09}$ \\
\hline $\log ($ market size $)$ & 0.07 & 0.06 & 0.11 & 0.02 & 0.02 & 0.06 & 0.10 & 0.03 \\
\hline Log-likelihood & \multicolumn{2}{|l|}{-615.82} & \multicolumn{2}{|c|}{-1577.04} & \multicolumn{2}{|l|}{-616.50} & \multicolumn{2}{|c|}{-1579.82} \\
\hline
\end{tabular}

The $\log$ (market size) terms are included in deviations from their mean level. Each regression also includes industry fixed-effects

brands. However, the results do indicate a statistically significant relationship between market size and the number of fringe brands. These findings are robust to both definitions of market size. These results suggest that the number of non-advertising brands increases with market size, while the number of advertising brands does not.

\subsection{Advertising and concentration}

We now test whether the escalation in advertising and non-escalation in the number of brands leads to a corresponding lower bound in concentration as predicted by the theory. Figure 2 contains a scatterplot of observed concentration levels and market size across industries and geographic areas. In accordance with the theory, separate plots are provided for advertising intensive and non-advertising intensive industries. We define advertising intensity as an industry's total in-sample advertising-to-sales ratio. The advertising versus non-advertising intensive industries consist of the respective upper and lower quartile industries based on advertising intensity. For the advertising intensive industries, there is little evidence of a linear correlation between concentration and market size. Even in the largest markets, concentration seldom falls below $20 \%$. Although not reported, a regression of concentration in each industry/market on market size reveals a statistically significant concave relationship under both market size definitions. ${ }^{16}$ In contrast, there is less evidence of a bound in non-advertising intensive industries where we observe concentration levels as low as $5 \%$. In this case, a regression of concentration in each industry/market on market size reveals a downward-sloping linear relationship.

As in the extant literature (e.g. Sutton 1991, Robinson and Chiang 1996 and Ellickson 2004a), we test the concentration prediction by estimating a

\footnotetext{
${ }^{16}$ Sutton (1991) also finds similar evidence of a non-monotonic relationship between concentration and market size for advertising-intensive industries. This non-monotonicity is consistent with the theory.
} 
(a) Concentration vs. Market Size (and estimated lower bounds) for advertising-intensive versus non-advertising-intensive industries.
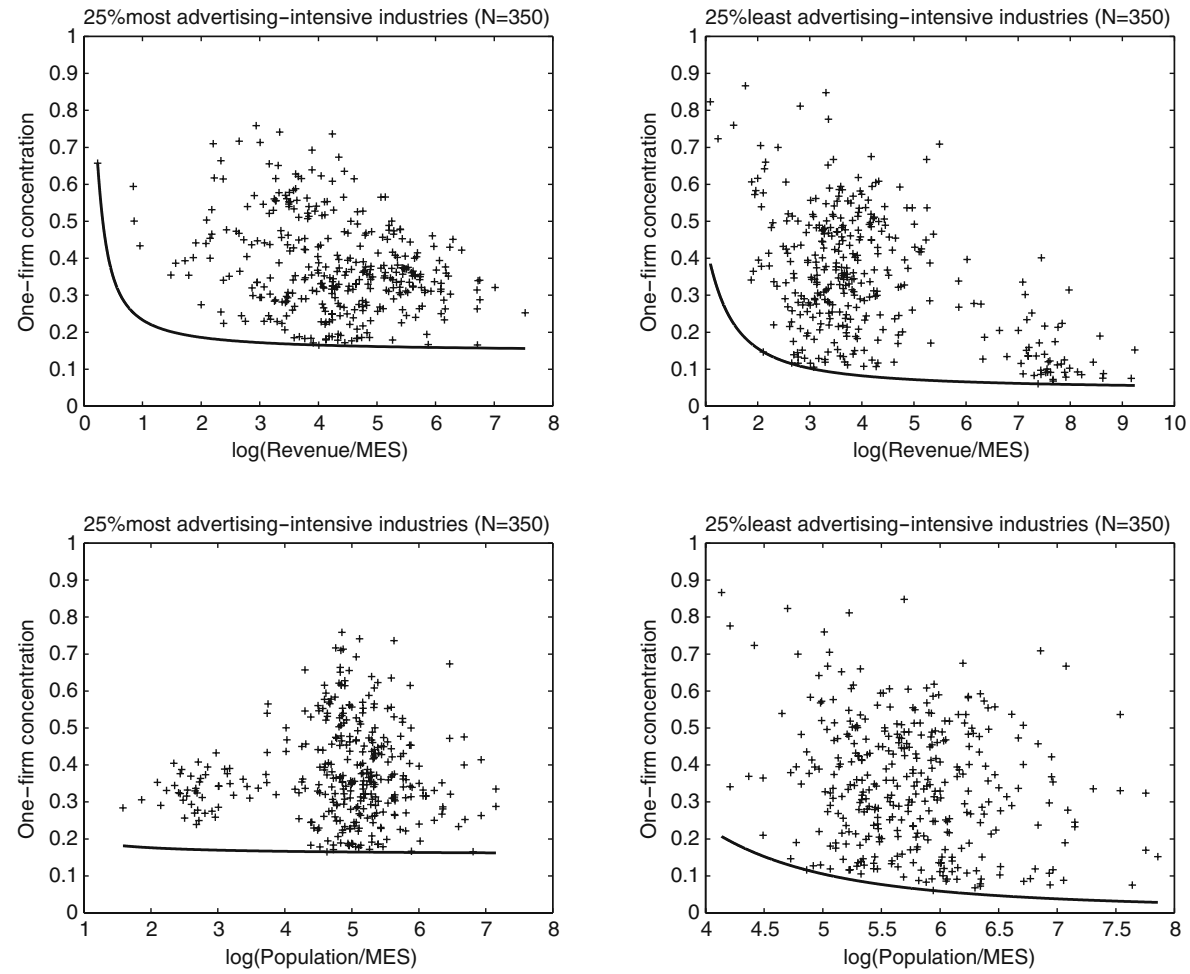

Fig. 2 Concentration vs. market size (and estimated lower bounds) for advertising-intensive versus non-advertising-intensive industries

lower bound function. Assume $C_{1}$ is drawn from a Weibull distribution. This assumption reflects the fact that $C_{1}$ is an extreme value of the distribution of brand shares and is necessarily bounded below at zero. Since $C_{1}$ is also constrained to lie between zero and one, we take a logit transformation: $\widetilde{C}_{1 m} \equiv$ $\log \left(\frac{C_{1 m}}{1-C_{1 m}}\right)$. Assume also that concentration in market $m$ is distributed as follows: $\tilde{C}_{1 m}=B$ (market size $\left.e_{m}\right)+\omega_{m}$, where $B$ (market size $\left.e_{m}\right)$ is a parametric function of observed market size that characterizes the lower bound. The random variable $\omega_{m}$ is a random draw from a Weibull distribution with shape parameter $\alpha$ and scale parameter $\beta$. Since we expect concentration to be inversely-related to market size in smaller markets, we follow the literature and specify $B$ (market size $e_{m}$ ) as a quadratic polynomial of the inverse of market size:

$$
\tilde{C}_{1 m}=a+\frac{b}{\text { market size }_{m}}+\frac{c}{\left(\text { market size }_{m}\right)^{2}}+\omega_{m}
$$


Table 6 Estimated lower bound functions for concentration in advertising-intensive and nonadvertising-intensive industries

\begin{tabular}{|c|c|c|c|c|c|c|c|c|}
\hline & \multicolumn{4}{|c|}{$\begin{array}{l}\text { Concentration versus } \\
\text { revenues/set-up costs }\end{array}$} & \multicolumn{4}{|c|}{$\begin{array}{l}\text { Concentration versus } \\
\text { population/set-up costs }\end{array}$} \\
\hline & \multicolumn{2}{|c|}{ Ad-intensive } & \multicolumn{2}{|c|}{$\begin{array}{l}\text { Non-ad-intensive } \\
\end{array}$} & \multicolumn{2}{|c|}{ Ad-intensive } & \multicolumn{2}{|c|}{ Non-ad-intensive } \\
\hline & Coefficient & s.e. & Coefficient & s.e. & Coefficient & s.e. & Coefficient & s.e. \\
\hline$a$ & -1.764 & 0.112 & -3.136 & 0.217 & -1.679 & 0.155 & -5.983 & 1.559 \\
\hline$b$ & 0.577 & 0.373 & 2.888 & 1.032 & 0.274 & 0.672 & 19.367 & 10.067 \\
\hline$c$ & -0.003 & 0.053 & 0.029 & 1.204 & 0.000 & 0.034 & -0.753 & 11.841 \\
\hline$\alpha$ & 1.225 & 0.035 & 1.812 & 0.051 & 1.237 & 0.035 & 2.114 & 0.054 \\
\hline$\beta$ & 2.050 & 0.080 & 2.211 & 0.083 & 2.015 & 0.080 & 2.395 & 0.098 \\
\hline$C_{1 \infty}$ & 0.146 & 0.041 & 0.042 & 0.022 & 0.157 & 0.054 & 0.003 & 0.011 \\
\hline Log-likelihood & 275.555 & & 397.032 & & 282.326 & & 428.447 & \\
\hline
\end{tabular}

This parametric formulation also provides us with a characterization of the limiting concentration as the market size approaches infinite: $a=\log \left(\frac{C_{1 \infty}}{1-C_{1 \infty}}\right)$ when market size approaches infinite.

The parameters for the bound function, $(a, b, c)^{\prime}$, and the Weibull distribution, $(\alpha, \beta)^{\prime}$, are estimated using the two-step procedure from Smith (1994). ${ }^{17}$ Standard errors are computed using the simulation method discussed in Smith (1994).

Estimation results are reported in Table 6. In general, we observe a steeper bound function for non-advertising intensive industries, driven mainly by the linear as opposed to the quadratic term. To illustrate, we plot the estimated bound functions in Fig. 2. Furthermore, the estimated limiting bounds reported in Table $6, C_{1 \infty}$, are much lower for non-advertising intensive than for advertising intensive industries (about 15\% and less than 5\% respectively). The estimated limiting bounds are not statistically different from zero at the $95 \%$ confidence level in the case of non-advertising intensive industries. These results are all consistent with the theory. Our findings suggest that concentration is bounded away from zero in advertising intensive industries, but not in non-advertising intensive industries. ${ }^{18}$ Interestingly, the findings of a relationship between concentration and advertising contrasts with an earlier literature in which the correlation between concentration levels and advertising levels in consumer goods industries were found to be small and, often, statistically insignificant (e.g. Telser 1964 and Comanor and Wilson

\footnotetext{
${ }^{17}$ In the first stage, we estimate $(a, b, c)^{\prime}$ from Eq. 2 using a simplex search subject to the constraint $\tilde{C}_{1 m}=a+\frac{b}{\text { market size } m}+\frac{c}{\left(\text { market size }_{m}\right)^{2}}+\omega_{m} \geq 0$. In the second stage, parameters $(\alpha, \beta)^{\prime}$ are estimated by fitting the first-stage prediction errors to a Weibull distribution.

${ }^{18}$ Although not reported, we also examined the lower bound in concentration separately for advertised brands and non-advertised brands. We estimate a limiting concentration level of about 0.15 for advertised brands and 0.0082 for non-advertised brands. These findings are also consistent with the theory insofar as the subsegment of non-advertised brands fragments in larger markets. Results are available from the authors upon request.
} 
1974). The contrast to earlier findings is likely due both to the quality of the data used herein as well as the use of an approach guided by game theory.

\section{Conclusions}

Collectively, the results indicate that advertising intensive industries appear to remain concentrated irrespective of market size. Our data allow us to study the underlying sources of this concentration. We observe an escalation in the level of advertising in larger markets. For those industries that advertise, the number of advertising brands appears to be independent of the size of the market. However, increasing the market size does lead to an escalation in the number of unadvertised "fringe" brands. Hence, in larger markets we tend to see better (i.e. more heavily advertised) brands rather than more advertised brands. These results are consistent with the basic ESC model whereby advertising generates economies of scale even in very large markets. In this respect, our findings are consistent with a model in which advertising is borne mainly as a fixed and sunk cost, as opposed to a variable cost. Furthermore, the results are consistent with a model in which branding increases consumer willingnessto-pay in a manner similar to a model of vertical product differentiation, as opposed to a model of horizontal differentiation.

These results provide an economic rationale for some of the geographic differences in category market shares described in Bronnenberg et al. (2007). The results herein do not speak to the persistence results in Bronnenberg et al. (2007) nor to the asymmetries of the brand shares of specific firms. In a companion piece, Bronnenberg et al. (2009), we look at the historic entry patterns within a subset of the categories to explain the persistence and asymmetry.

An interesting extension of the results would be to establish why the degree of advertising intensity varies across CPG industries. In the current paper, we use the advertising-to-sales ratio to partition our industries into adintensive and non-ad-intensive, which is based on equilibrium outcomes. A preferable approach would be to use a measure of the marginal effectiveness of advertising. An interesting direction for future research in this area would be to add more structure to the empirical analysis. Our current descriptive models help us identify evidence of a long-run effect of advertising on industrial market structure. However, the estimation of a structural demand system, by industry, could further enable one to measure the marginal effect of advertising on sales and to analyze the implications for equilibrium advertising levels in contrast with prices and promotions. Such an approach might also provide some insights into why CPG industries differ to such a degree in their advertising intensities.

Finally, our findings are consistent with the notion that advertising creates economies of scale that matter even in very large markets. This result obtains when advertising represents a fixed and sunk cost that raises consumer willingness-to-pay in a manner analogous to vertical product differentiation. 
Clearly, future research on the precise microeconomic role of advertising and how it might influence consumer willingness-to-pay in this manner would be of tremendous interest.

Acknowledgements We are very grateful to Emek Basker, Tim Conley, Matt Gentzkow, Avi Goldfarb, Jonathan Levin, Sanjay Sood, Raphael Thomadsen and Florian Zettelmeyer for insightful comments and discussions. We also thank seminar participants at Cornell University, Duke University, Harvard, MIT, New York University, the University of Chicago, the Yale SOM, the 2004 Choice Symposium in Estes Park, Colorado, the 2004 Marketing Camp at Leuven, the 2005 NBER Winter I.O. meetings, the 2005 CRES conference at Olin and the 2005 SICS conference at Berkeley for valuable feedback and helpful suggestions. We are also grateful to Ed Lebar of Young \& Rubicam Brands for providing us with the BAV data and to Jeff Hermann of Nielsen Media Research for the historical advertising data. The authors are also grateful for research support from MSI, grant \#4-1301. Bronnenberg thanks the NSF for research support under grant SES 0644761. Dhar thanks the Neubauer faculty fund for research support. Dubé acknowledges the support of the Kilts Center for Marketing.

Open Access This article is distributed under the terms of the Creative Commons Attribution Noncommercial License which permits any noncommercial use, distribution, and reproduction in any medium, provided the original author(s) and source are credited.

\section{A Theoretical framework}

This Appendix briefly outlines the technical details of the model and results from Shaked and Sutton (1987) and Sutton (1991). Consider a discrete choice model of consumer demand with both horizontal and vertical product differentiation. Define a product $x$ with characteristics $(\psi, \eta)$ where $\psi$ is vertical and $\eta$ is horizontal. Assume a consumer $h$ is described by his income, $Y_{h}$, where $Y_{h} \sim f(Y, \alpha)$, and an ideal point in horizontal product attribute space, $\alpha_{h}$. If consumer $h$ chooses brand $x$, he obtains utility:

$$
\begin{aligned}
U(x) & =u\left(\psi,\left|\omega-\alpha_{h}\right|, Y_{h}-p\right) \\
& =u\left(\psi, d, y_{h}\right)
\end{aligned}
$$

where $u_{\psi}>0, u_{d}<0, u_{\psi y}>0$ and $u_{y}$ and $\left|u_{d}\right|$ are bounded above. This model is sufficiently general to include many of the popular empirical models used in the brand choice literature such as the random coefficients multinomial logit and probit.

Firms play the following three-stage game. In the first stage, they decide whether or not to enter a market. In the second stage, they pick product attribute levels $(\psi, \eta)$ at $\operatorname{cost} F(\psi)$ where $F$ is strictly positive and increasing in the level of quality, $\psi$, and $\frac{F^{\prime}}{F}$ is bounded above. This latter assumption ensures that as quality levels increase, the incremental costs to raise quality do not become arbitrarily large. In the third stage, firms play a Bertrand pricing game conditional on the product attributes and marginal costs $c(\psi)$, where $c(\psi)<\bar{Y}<\max \left(Y_{h}\right)$. These assumptions imply that higher quality firms also have higher marginal costs. However, marginal costs are bounded above by some income level below the maximum income level and, hence, there will 
always be some consumers willing to pay for arbitrarily large quality levels. In other words, costs increase more slowly than the marginal valuation of the "highest-income"consumer.

The following propositions are proved in Shaked and Sutton (1987).

Proposition 1 If $u_{\psi}=0$ (i.e. no vertical differentiation), then for any $\varepsilon>0$, there exists a number of consumers $S^{*}$ such that for any $S>S^{*}$, every firm has an equilibrium market share less than $\varepsilon$.

This proposition captures the fact that, even with horizontal product differentiation, concentration falls in large markets because the economies of scale from the constant entry costs cease to matter.

When $u_{\psi}>0$, the following proposition holds:

Proposition 2 There exists an $\varepsilon>0$ such that at equilibrium, at least one firm has a market share larger than $\varepsilon$, irrespective of the market size.

This proposition captures the fact that when a fixed and sunk advertising cost can raise consumer willingness-to-pay, then advertising generates economies of scale that matter even in very large markets. As a result, entry is limited and markets remain concentrated.

\section{References}

Advertising Age (1994). Big G's cereals sag, drag on bottom line (Vol. 4).

Allison, R. J., \& Uhl, K. P. (1964). Influence of beer brand identification on taste perception. Journal of Marketing Research, 1, 36-39.

Andras, T. L., \& Srinivasan, S. S. (2003). Advertising intensity and R\&D intensity: Differences across industries and their impact on firm's performance. International Journal of Business and Economics, 2(2), 167-176.

Berry, S. T. (1992). Estimation of a model of entry in the airline industry. Econometrica, 60(4), 889-917.

Berry, S., \& Waldfogel, J. (2003). Product quality and market size. Wharton School, Mimeo.

Blattberg, R., \& Neslin, S. (1990). Sales promotions: Concepts, methods and strategies. Englewood Cliffs, New Jersey: Prentice Hall.

Bresnahan, T. S., \& Reiss, P. (1991). Entry and competition in concentrated markets. Journal of Political Economy, 95(5), 977-1009.

Bronnenberg, B. J., Dhar, S. K., \& Dubé, J. P. (2007). Consumer packaged goods in the United States: National brands, local branding. Journal of Marketing Research, 44(1), 4-13.

Bronnenberg, B. J., Dhar, S. K., \& Dubé, J. P. (2009). Brand history, geography and the persistence of brand shares. The Journal of Political Economy, 117(1), 87-115

Business Editors (2002). CPG firms continue to spend less than $2 \%$ of their advertising budgets online; eMarketer finds that the consumer package goods industry lags other sectors in advertising online. Business Wire. http://www.thefreelibrary.com/CPG+Firms+Continue+to+ Spend+Less+Than $+2 \% 25+$ Of + Their+Advertising+Budgets...-a085972312.

Campbell, J. R., \& Hopenhayn, H. A. (2004). Market size matters. Journal of Industrial Economics

Chakravarti, A, \& Janiszewski, C. (2004). The influence of generic advertising on brand preferences. Journal of Consumer Research, 30, 487-502.

Comanor, W. S., \& Wilson, T. A. (1974). Advertising and market power. Cambridge: Harvard University Press. 
Dhar, S. K., \& Hoch, S. J. (1997). Why store brand penetration varies by retailer. Marketing Science, 16(3), 208-227.

Dick, A. A. (2004). Competition in banking: Exogenous vs endogenous sunk costs. Federal Reserve Bank New York, Mimeo.

D'Souza, G., \& Rao R. C. (1995). Can repeating an advertisement more frequently than the competition affect brand preference in a mature market?" Journal of Marketing, 59, 32-42.

Ellickson, P. B. (2004a). Does sutton apply to supermarkets?. Duke University, Mimeo.

Ellickson, P. B. (2004b). Supermarkets as a natural oligopoly. Duke University, Mimeo.

Ellison, G., \& Glaeser, E. L. (1997). Geographic concentration in U.S. manufacturing industries. Journal of Political Economy, 105(5), 889-927.

Ellison, G., \& Glaeser, E. L. (1999). The geographic concentration of industry: Does natural advantage explain agglomoration. American Economic Review, 89(2), 311-316

Hoyer, W. D., \& Brown, S. P. (1990). Effects of brand awareness on choice for a common, repeatpurchase product. Journal of Consumer Research, 17, 141-148.

Keller, K. L. (1987). Memory factors in advertising: The effect of advertising retrieval cues on brand evaluations. Journal of Consumer Research, 14, 316-333.

Keller, K. L. (2003). Strategic brand management. New Jersey: Prentice Hall.

Krugman, P. (1991). Increasing returns and economic geography. Journal of Political Economy, 99(3), 483-499.

Mazzeo, M. J., \& Cohen, A. M. (2004). Market structure and competition among retail depository institutions. Northwestern University, Mimeo

Nedungadi, P. (1990). Recall and consumer consideration sets: Influencing choice without altering brand evaluations. Journal of Consumer Research, 17(3), 263-276.

Robinson, W. T., \& Chiang, J. (1996). Are sutton's predictions robust?: Empirical insights into advertising, R\&D, and concentration. Journal of Industrial Economics, 44, 389-408.

Shaked, A., \& Sutton, J. (1983). Natural Oligopolies. Econometrica, 51(5), 1469-1483.

Shaked, A., \& Sutton, J. (1987). Product differentiation and industrial structure. Journal of Industrial Economics, 36, 131-146.

Smith, R. L. (1994). Nonregular regression. Biometrika, 81, 173-183.

Sutton, J. (1991). Sunk costs and market structure, price competition, advertising, and the evolution of concentration. Cambrigde: MIT.

Sutton, J. (2003). Market structure - the bounds approach. In R. Porter \& M. Armstrong (Eds.), Handbook of industrial organization (Vol. 3).

Telser, L. G. (1964). Advertising and competition. Journal of Political Economy, 72(6), 537-562. 